\title{
Mean platelet volume: An economical diagnostic marker of cardiovascular risk assessment in altered fasting blood glucose levels
}

\author{
Shivali Kapoor ${ }^{1}$, Manjit Kaur², Amrit Pal Singh Rana ${ }^{3}$, A Suryanarayan ${ }^{4}$ \\ ${ }^{1}$ Junior Pathologist, Lister Metropolis Laboratories, Chennai, Tamil Nadu, India, ${ }^{2}$ Assistant Professor, Department of Pathology, GGS Medical \\ College, Faridkot, ${ }^{3}$ Assistant Professor, Department of Surgery, GGS Medical College, Faridkot, ${ }^{4}$ Vice President Operations, Lister Metropolis \\ Laboratories, Chennai, Tamil Nadu, India and Srilanka
}

\section{A B S TR A C T}

Background: Platelets with altered morphology or large size are more thrombogenic and are likely to be associated with increased risk of vascular disease. Platelet parameters especially high mean platelet volume (MPV) has been reported in diabetic patients as major contributing factor. The aim of the present study was to find correlation between fasting blood glucose value and hematological variables (PC and MPV), not only in diabetics, but also in the normoglycemic subjects and patients with impaired fasting blood glucose levels. Materials and Methods: In the present study 3471 subjects were analyzed retrospectively and categorized into three groups based on the fasting blood glucose levels as Group I - normoglycemics (FBG $\leq 109 \mathrm{mg} / \mathrm{dl}$, $\mathrm{n}=1158$ ), Group II- impaired fasting blood glucose (FBG $\leq 126 \mathrm{mg} / \mathrm{dl}, \mathrm{n}=1158$ ) and Group III - Diabetics (FBG $\geq 127 \mathrm{mg} / \mathrm{dl}, \mathrm{n}=1155)$. Results: We found progressive increase in value of MPV with the increasing FBG levels, in the following order: G1 (8.44 $\pm 0.842 \mathrm{fl})$, $\mathrm{G} 2(8.98 \pm 0.898 \mathrm{fl}), \mathrm{G} 3(9.31 \pm 0.967 \mathrm{fl})$. The platelet count however, did not show much statistical significance with rising glucose levels. Conclusions: MPV increased proportionally with increasing plasma glucose levels. Although the variation between the normoglycemics and impaired fasting group was not very significant, the parameters still showed progressive increase with rising sugar levels significant in diabetic group.

Key words: Diabetes mellitus, Impaired fasting blood glucose, Mean platelet volume, Platelets counts

\section{INTRODUCTION}

Diabetes mellitus (DM) is a global health problem. Most DM related deaths are due to the increased risk of developing atherosclerosis and it is associated with various disturbances at the cellular as well as metabolic levels. ${ }^{1,2}$ Impaired fasting blood glucose commonly termed as prediabetes, is also a common glycemic disorder in the general population and usually precedes the clinical overt diabetes for a variable period. A metabolic and vascular disturbance at the cellular level due to persistent hyperglycemia usually starts in prediabetic stage itself. Platelets attain larger size; contain increased number of dense granules as compared with smaller platelets hence become more prone for aggregation and thrombogenic. So these reactive platelets play important role in the development of vascular complications and their squeal i.e., increased risk of cardiovascular diseases. Activity of platelets is usually determined by very simple platelet indices like PC and MPV. Amongst that MPV is a proven marker of the platelet function and activation. ${ }^{3,45}$

\section{MATERIAL AND METHODS}

Retrospective analysis of the data was done in case of subjects from urban as well as semi-urban area of southern India, who had come for routine health checks at diagnostic laboratory. Patients who were on anti-platelet medications, 
on anti diabetic medications were excluded. Also patients suspected/known cases of leucocytic/platelet disorders, subjects with $\mathrm{Hb}<13 \mathrm{~g} / \mathrm{dl}$ in males \& $\mathrm{Hb}<11.5 \mathrm{~g} / \mathrm{l}$ in females as nutritional anaemia can increase the MPV and cause reactive thrombocytosis were not considered. Total of 3471 subjects were taken into consideration after re-evaluating the medical history, fasting blood glucose (FBG) levels, PC and MPV. All blood samples in these patients were obtained after overnight fasting (8 hours) in EDTA \& Fluoride vacutainers for measurement of complete blood counts and blood glucose respectively. All samples were run for blood glucose and complete blood counts within half an hour to avoid variations relating to old samples. Blood glucose levels were tested using automated biochemistry analyzer. The platelet count, MPV were done using automated blood cell counter. On the basis of FBG levels the categorization of the three groups was done according to the criteria defined by American Diabetes Association (ADA). ${ }^{6}$

Group I: Normoglycemics - FBG value being 70-109 mg/dl Group II: Impaired fasting glucose - FBG value being $110-126 \mathrm{mg} / \mathrm{dl}$

Group III: Diabetics - FBG value being $>127 \mathrm{mg} / \mathrm{dl}$.

Comparison between PC and MPV values in between all the three groups was done with the appropriate statistics.

\section{Statistical analysis}

Analysis of variance (ANOVA) has been used to find the significance of study parameters between the three groups. The Tukey LSD ALPHA (0.05) test was used to find the pair wise significance. Data were expressed as mean \pm standard deviation. P values less than 0.05 were considered statistically significant.

\section{RESULTS}

Mean FBG, MPV and PC was measured in different groups of 3471 subjects and were correlated statistically (Table 1).

Significant increase in value of MPV was seen in diabetics along with progressive increase with rising sugar levels in other groups. The platelet count however, did not show much statistical significance (Table 2).

\section{DISCUSSION}

Diabetes Mellitus is a major health trouble and is an important cause of cardiovascular morbidity and mortality. Increased platelet activity in the form of altered morphology is considered to play key role in the development of various vascular complications. Out of the various proposed pathogenic mechanisms, significant

\begin{tabular}{|c|c|c|c|}
\hline $\begin{array}{l}\text { Blood } \\
\text { Parameters }\end{array}$ & $\begin{array}{c}\text { Group I } \\
(n=1158)\end{array}$ & $\begin{array}{l}\text { Group II } \\
(n=1158)\end{array}$ & $\begin{array}{l}\text { Group III } \\
(n=1155)\end{array}$ \\
\hline FBG (mg/dl) & $88.35 \pm 7.3$ & $113.22 \pm 5.1$ & $178.84 \pm 60.5$ \\
\hline MPV (fl) & $8.44 \pm 0.842$ & $8.98 \pm 0.898$ & $9.31 \pm 0.967$ \\
\hline PC (lacs/cmm) & $262.15 \pm 61.640$ & $248.92 \pm 57.376$ & $245.29 \pm 69.781$ \\
\hline
\end{tabular}

are a) Osmotic swelling of platelets due to persistent hyperglycemia and its metabolic products and b) Shorter life span of platelets in diabetics leading to higher platelet turn over with younger platelets being more active and thrombogenic and are associated with raised $\mathrm{MPV}^{7,8}$ Also it has been noticed that platelets from patients with altered fasting glucose also have dysregulated signalling pathways as well as have significantly higher von-willebrand factor levels in serum, resulting in an increased tendency to activate and aggregate. ${ }^{9,10}$ This alteration can be detected by platelets indices such as platelet count and platelet volume in relation with increasing fasting glucose levels. ${ }^{4,5}$

In the current study large sample comprising of 3471 were taken into consideration and ADA criteria of impaired fasting glucose (IFG) was adopted and values of PC as well as MPV were studied. As per this criteria threshold levels for IFG was lowered up to $100-125 \mathrm{mg} / \mathrm{dl}$ of fasting plasma glucose in 2003 for better prediction of future diabetes incidence. ${ }^{6,11}$

Many studies conducted in past also have emphasized high MPV as a risk factor for the vascular complications especially in diagnosed cases of diabetes and IFG. ${ }^{5,8,9,12,13}$ Shah et al. reported a significant correlation between MPV and the degree of glycemic control in diabetic patients. They suggested that the positive relationship between an increased glucose level and increased MPV is a unique phenomenon of diabetes. ${ }^{8}$ But only few studies revealed correlation between MPV and normoglycemics as well. ${ }^{14,15}$

In the present study, it was observed that MPV was high in patients with IFG, and was further higher in diabetics in comparison with normal FBG levels. A positive correlation between increasing fasting blood glucose levels and MPV was observed which was in concordance with the study done by Shimodaira M et al with in 1876 Japanese subjects with similar study design. ${ }^{14}$ In an another study conducted by Zuberi B et al on 612 subjects in Pakistan also suggested positive correlation between increased MPV with altered FBG levels. ${ }^{15}$

Although some uncertainty remains, as Kim et al do mentioned negative correlation between MPV and FBG with normal glucose tolerance and intermittent hyperglycemia in 3098 Korean subjects. A result of their 


\begin{tabular}{|c|c|c|c|c|c|}
\hline $\begin{array}{l}\text { Blood } \\
\text { Parameters }\end{array}$ & $\begin{array}{c}\text { Group I vs } \\
\text { Group II, Group III }\end{array}$ & $\begin{array}{c}\text { Group II vs } \\
\text { Group III }\end{array}$ & $\begin{array}{c}\text { Group II vs } \\
\text { Group I }\end{array}$ & $\begin{array}{c}\text { Group III vs } \\
\text { Group I }\end{array}$ & $\begin{array}{l}\text { Group III vs } \\
\text { Group II }\end{array}$ \\
\hline MPV & $P<0.001$ & $P<0.001$ & $P<0.001$ & $P<0.001$ & $P<0.001$ \\
\hline Platelets count & $P<0.001$ & $P<0.001$ & $P>0.05$ & $P>0.05$ & $P<0.001$ \\
\hline
\end{tabular}

study suggests that the positive relationship between an increased glucose level and increased MPV is seen in diabetes only. ${ }^{16}$ But on the other hand in contrary Shyke $\mathrm{K}$ et al have strongly emphasized in their study conducted on 10,913 subjects that people with high normal fasting glucose levels show more cardiovascular risk than low normal fasting glucose levels. Increased cardiovascular risk in these patients may be an indirect evidence of altered MPV in altered FBG, as in a study conducted on mice has revealed that, insulin induces the megakaryocytes hence producing larger platelets. ${ }^{17,18}$

While working on platelet parameters, significant decrease in PC of patients with IFG and DM in contrast to normoglycemics was observed. Also a statistically significant increase of PC in DM than normal FBG along with no significant difference between MPV has been mentioned in the literature. One study conducted showed positive correlation between FBG with MPV as discussed earlier but no significant increase was noted in PC. ${ }^{19,20}$ Thus it was concluded that platelet counts have unpredictable behaviour in relation with FBG levels.

Recent data from our study supports the possibility of increase in MPV with rise in fasting plasma glucose levels in large group of subjects. Mean platelet volume (MPV) being a simple, economical test, done as a part of complete blood counts in modern era of automated blood analyzers can serve as an effective tool in monitoring the patients for platelet dysfunction and hence increased thrombogenecity especially in with altered blood glucose metabolism without any overt haematological disorder. It is emphasized that it can be very simple, quick and cost effective tool especially in developing country like India with limited resources to detect early vascular complications in patient with altered glucose metabolism. Keeping in view the uncertainties regarding results of various studies conducted in past further large prospective studies should be conducted to confirm the clinical utility of this marker and also to elucidate the association between MPV and platelet hyperreactivity in relation with fasting plasma glucose levels.

\section{ACKNOWLEDGEMENT}

We are grateful to Dr. Ghansham Sharma (PhD Statistics) for his statistical assistance. We would also like to express our appreciation to Mr Ramesh Senior Lab Manager, Lister
Metropolis laboratories for his technical support and for help in finding vast data for the study.

\section{REFERENCES}

1. Deferonzo RA and Abdul-Ghani M. Assesment and treatment of cardiovascular risk in prediadetes: Impaired glucose tolerance and impaired fasting glucose. American Journal of Cardiology 2011;108:3B-24B.

2. Lee M, Saver JL, Hong KS, Song S, Chang KH and Ovbiagele B. Effect of pre-diabetes on future risk of stroke: Meta-analysis. British Medical Journal 2012;344:e3564.

3. Vizioli L, Muscari $S$ and Muscari A. The relationship of mean platelet volume with the risk and prognosis of cardiovascular disease. International Journal of clinical Practice 2009;63:1509-1515.

4. Tavil Y, Sen N, Yazici HU, Abaci A and Cengel A. Mean platelet volume in patients with metabolic syndrome and its relationship with coronary artery disease. Thrombosis Research 2007;120:245-250.

5. Hekimosy Z, Payzin B, Ornek T and kandogan G. Mean platelet volume in type 2 diabetic patients. Journal of Diabetes and its Complications 2004;18:173-176.

6. American Diabetes Association: Diagnosis and classification of diabetes mellitus. Diabetes care 2008;31:S55-S60.

7. Demirtunc $R$, Duman D, Basar M, Bilgi $M$, Teomete $M$ and Grip T. The relationship between glycemic control and platelet activity in type 2 diabetes mellitus. Journal of Diabetes and its Complication 2009; 23:89-94.

8. Shah B, Sha D, Xie D, Mohler ER $3^{\text {rd }}$ and Berger JS. The relationship between diabetes, metabolic syndrome, and platelet activity as measured by mean platelet volume: The national health and nutrition examination surveys, 1999-2004. Diabetes Care 2012; 35:1074-1078.

9. Muscari A, De Pascalis S, Cenni A, Ludovico C, Castaldini N, Antonelli S, et al. Determinants of mean platelet volume (MPV) in an elderly population: Relevance of body fat, blood glucose and ischaemic electrocardiographic changes. Thrombosis and Haemostasis 2008; 99:1079-1084.

10. Boston F and Coban E. The relationship between levels of von willebrand factor and mean platelet volume in subjects with isolated impaired fasting glucose. Medical Science Monitor 2011; 17(6): PR1-PR4.

11. Expert Committee on the Diagnosis and Classification of Diabetes Mellitus. Report of the expert committee on the diagnosis and classification of diabetes mellitus. Diabetes care 2003; 26:S5-S20.

12. Papanas N, Symeonidis G, Maltezos E, Mavridis G, Karavageli E, Vosnakidis T, et al. Mean platelet volume in patients with type 2 diabetes mellitus. Platelets 2004; 15:475-478.

13. Coban $\mathrm{E}$, Boston $\mathrm{F}$ and Ozdogan $\mathrm{M}$. The mean platelet volume in subjects with impaired fasting glucose. Platelets 2006; 17:67-69.

14. Shimodaira M, Niwa T, Nakajima K, Kobayashi M, Hanyu N and Nakayama T. Correlation between mean platelet volume and fasting plasma glucose levels in prediabetic and normoglycemic individuals. Cardiovascular Diabetology 2013;11:12-14. 
15. Zuberi B, Akhtar $\mathrm{N}$ and Afsar S. Comparison of mean platelet volume in patients with diabetes mellitus, impaired fasting blood glucose and non-diabetic subjects. Singapore Medical Journal 2008; 49:114

16. Kim JH, Kang JI, Kim JW, Kim SY and Bae HY. The relationship between mean platelet volume and fasting plasma glucose differs with glucose tolerance status in a Korean population: Gender differences. Platelets 2013; 24:469-473.

17. Shyke K, Amir T, Shlomo S and Yechezkel S. Fasting glucose levels within the high normal range predict cardiovascular outcome. American Heart Journal 2012; 164:111-116.

18. Moore SF, Williams CM, Brown E, Blair TA, Harper MT, Coward RJ, et al. Loss of the insulin receptor in murine megakaryocytosis/ platelets causes thrombocytosis and alteration in IGF signalling. Cardiovascular Research 2015;107:9-9.

19. Akinsegun A, Olusola DA, Sarah JO, Olajumoke O, Adewumi A, Majeed $O$, et al. Mean platelet volume and platelet counts in type 2 Diabetes: Mellitus on treatment and non-diabetic mellitus controls in Lagos, Nigeria. The Pan African Medical Journal 2014;18:42.

20. Umadevi SV, John J and John N. Platelet count, mean platelet volume, serum creatinine and delayed clotting time as surrogate markers of type 2 diabetes mellitus. International Journal of Biological and Medical Research 2014; 5:3970-3974.

\footnotetext{
Authors Contribution:

SK and MK - Concept and design of the study, reviewed the literature, manuscript preparation and critical revision of the manuscript; APS - review of literature and helped in preparing first draft of manuscript; AS - Conceptualized study

Source of Support: Nil, Conflict of Interest: None declared.
} 